Research Article

\title{
On the Rolling Noise Reduction by Using the Rail Damper
}

\author{
Mădălina Dumitriu ${ }^{1, *}$ and Ioan Cristian Cruceanu ${ }^{2}$ \\ ${ }^{1}$ Department of Railway Vehicles, University Politehnica of Bucharest, 313 Splaiul Independenţei, 060042, Bucharest, Romania \\ ${ }^{2}$ S.C. Atelierele CFR Griviţa S.A., 359 Calea Griviţei, 010718, Bucharest, Romania.
}

Received 7 July 2017; Accepted 15 December 2017

\begin{abstract}
This paper discusses the possibilities of mitigation of the rolling noise in the railway vehicles by means of the rail dampers. In this context, the generation mechanism for this type of noise is therefore described. The active techniques and methods of control over the rolling noise, focused on the track infrastructure and the rolling stock are enumerated. The highlight is the rail damper from the perspective of its practical implementation and the review of the most important results concerning the reduction of the rolling noise in many European countries. The conclusions validate the difficulty found in a correct evaluation of the efficiency in the rail dampers and of their effect upon the track infrastructure requirements for costly investments.
\end{abstract}

Keywords: railway vehicle, rolling noise, rail damper, track decay rate

\section{Introduction}

As a reaction to the important role played by the railway transport in the overall transportation greening, the issue of the railway noise has become a top priority in many European countries. This type of transport is commonly acknowledged as a more economical, safer and ecological means of transportation, thus with the potential to operate with considerably less pollution, energy use and $\mathrm{CO}_{2}$ emissions per passenger-km than road or air [1].

The constant trend in the last decades in increasing the train velocity, tonnage and traffic intensification has led to difficulties related to the environment pollution due to the amplification in the noise emission. A 2010 report issued by the European Environment Agency (EEA) states that the railway noise affects circa 12 million people in the EU Member States during the day, as they have a noise exposure above $55 \mathrm{~dB}$, whereas the number lowers to 9 million for the night, with the exposure over $50 \mathrm{~dB}$. However, the numbers are higher because the collected data concern the agglomerations of more than 250,000 inhabitants, for the main railways routes of over 60,000 trains per year [2].

To maintain the position of the railway transport within the system of the transportation as a 'green' means, more measures to reduce the railway noise pollution have been taken, classified into passive and active measures. The most significant passive measures used to scale down the impact of the railway noise on the environment require the use of noise protection walls and insulating windows. Nevertheless, these measures are only locally efficient and need large investments to protect the extended railway networks.

Unlike the passive measures that intend to curtail the impact of the noise upon the environment, the active ones

\footnotetext{
*E-mail address: madalinadumitriu@yahoo.com

ISSN: 1791-2377 @ 2017 Eastern Macedonia and Thrace Institute of Technology. All rights reserved. doi:10.25103/jestr.106.12
}

aim to control the noise level as they are oriented towards the noise source. The noise control via active measures firstly involves the identification of the main source of noise. The most important noise source in their large group in the railway vehicles is the rolling noise, coming from the interaction of wheel and rail during running on straight track, with no discontinuities in the rolling surfaces. Other sources supply to the total level of railway noise, such as the traction noise, aerodynamic noise, curve squeal, bridge noise and braking noise [3].

The contribution of the most important noise sources rolling noise, traction noise and the aerodynamic noise - to the overall railway noise depends on the train speed, as seen in Fig. 1. For low velocities of up to $30 \mathrm{~km} / \mathrm{h}$, the traction noise is the dominant noise source, whereas the rolling noise plays that role for the $30 \ldots 270 \mathrm{~km} / \mathrm{h}$ interval. As for the aerodynamic noise, very large velocities make it audible.

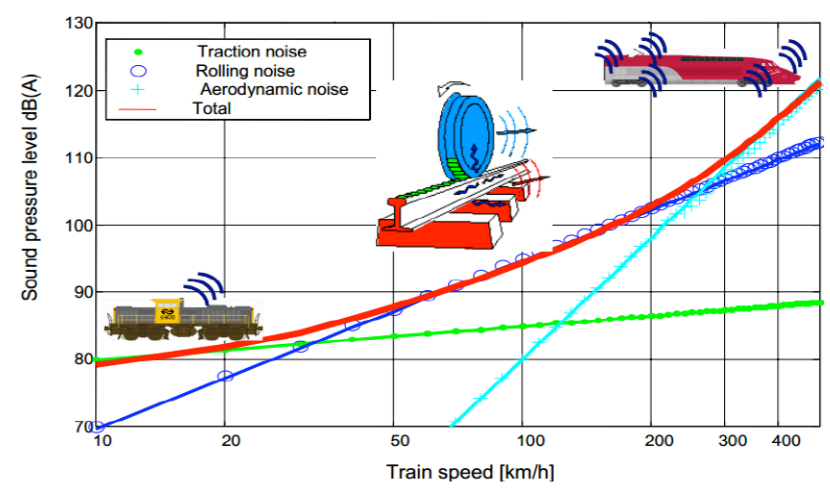

Fig. 1. Sources of railway noise versus train speed [4].

Generally speaking, the predominant noise sources also are dependent on the train type (see Table 1). Herein is thus confirmed the importance of the rolling noise compared to the traction or the aerodynamic noises. 
Table 1. Importance of noise sources [5].

\begin{tabular}{l|c|c|c}
\hline \multicolumn{1}{c|}{ The train type } & Rolling noise & $\begin{array}{c}\text { Traction } \\
\text { Noise and } \\
\text { Auxiliary } \\
\text { Systems }\end{array}$ & $\begin{array}{c}\text { Aerodynamic } \\
\text { noise }\end{array}$ \\
\hline Freight trains & Relevant & $\begin{array}{c}\text { Highly } \\
\text { relevant } \\
\text { Highly } \\
\text { Intercity trains }\end{array}$ & Relevant \\
Relevant & $\begin{array}{c}\text { Highly } \\
\text { relevant } \\
\text { Highly } \\
\text { relevant }\end{array}$ & Nelevant \\
Relevant & Not relevant \\
\hline
\end{tabular}

The predominant noise source can vary, too, in dependence on certain particular situations - travelling at a constant speed, acceleration and deceleration, stationary noise in and around stations and the shunting noise, which features a variety of noise sources (see Table 2).

Table 2. Noise sources relevant for particular situations [5].

\begin{tabular}{|c|c|c|c|}
\hline $\begin{array}{c}\text { Noise } \\
\text { situation }\end{array}$ & $\begin{array}{c}\text { Constant speed } \\
\text { and } \\
\text { acceleration/deceleration } \\
\end{array}$ & $\begin{array}{l}\text { Stationary } \\
\text { noise }\end{array}$ & $\begin{array}{l}\text { Shunting } \\
\text { and other }\end{array}$ \\
\hline $\begin{array}{l}\text { Noise } \\
\text { sources }\end{array}$ & $\begin{array}{l}\text { Rolling } \\
\text { Traction/auxiliary } \\
\text { Aerodynamic } \\
\text { (Locally: Squeal, } \\
\text { Impact, bridges) }\end{array}$ & $\begin{array}{l}\text { Traction/ } \\
\text { auxiliary }\end{array}$ & $\begin{array}{l}\text { Squeal/Imp } \\
\text { act } \\
\text { Traction/ } \\
\text { auxiliary } \\
\text { Rolling }\end{array}$ \\
\hline
\end{tabular}

The paper will also comment on the most important railway noise source - the rolling noise - and the means to mitigate it by using the rail dampers. There is a section for the mechanism of generating the rolling noise, followed by another that enumerates the techniques and methods of attenuating the rolling noise. But the highlight of the paper is the rail damper. In this context, a short presentation of the building and functional principle of the rail damper is introduced, along with a discussion about the efficiency of this damper, described by the track decay rate. Next, the first practical implementations of the rail dampers within three major projects OFWHAT, VONA and Silent Track are dealt with. A distinct section is intended for the display of the most used rail dampers, such as the ones manufactured by Schey \& Veith, TATA Steel, Vossloh and STRAIL. In the end, a review of the most significant results in noise reduction is provided, derived from using the rail dampers in many European countries.

\section{Rolling noise generation}

As said earlier, the rolling noise is the most important source of railway noise coming from the excitation of the structural vibrations in the wheel/rail system, due to the overlapping in the roughness of the rolling surfaces.

The fact that the roughness of the rolling surfaces underlies the noise generation has been known for a long time, but credits should be given to Remington [7, 8] to have been designed the first mechanical model regarding the generation of the rolling noise and found the mathematical equations that allow the calculation of the noise level. Remington believes that, during rolling and against the wheel/rail contact, the roughness of the two rolling surfaces overlap each other and make the two bodies carry out relative motions - the model of the imposed displacement. The bodies in contact are elastic and they distort themselves in the contact patch under the action of the load on wheel, thus taking the shape of an ellipse. The contact ellipse impacts the efficiency with which the roughness of the rolling surfaces excites the motion of the wheel/rail system in acting like a filter, in the sense that it curtails the influence of the roughness whose wavelength is shorter than the length of the contact ellipse.

The overlap of the roughness in the rolling surfaces leads to the development of the dynamic forces that also act upon the wheel and the rail. The size of these forces is influenced by the rigidity in the wheel/rail contact. The response of the wheel and of the rail to the action of the contact dynamic forces differs, according to the impedances of the two bodies. The vibrations in the contact ellipse patch propagate in the entire mass of the bodies and they manifest as structural vibrations. There mainly emerge structural vibrations in a vertical plan and also in the horizontal plan. The latter ones come from the fact that the wheel has a geometric asymmetry, the vertical force only operates in the vertical plan of the rail under exceptional circumstances and there are forces derived from the lateral creepage. These vibrations pass-through the wheel surface and of the rail, respectively, in the open air and, hence, the wheel and the rail become acoustic radiators. The acoustic waves from the two bodies combine and propagate themselves in the environment under the form of the rolling noise.

Figure 2 shows the model for the generation of the rolling noise as a flow chart and Figure 3 illustrates the mechanism of generation of the rolling noise above described.

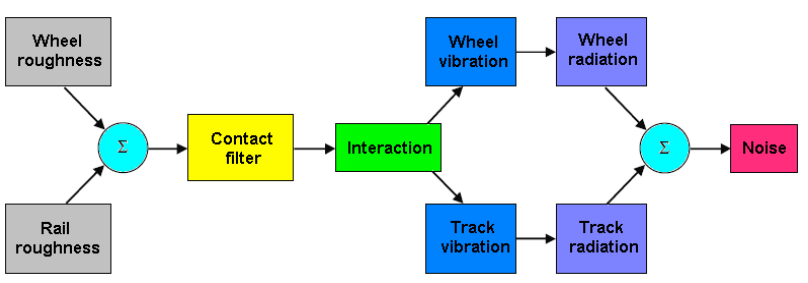

Fig. 2. Model for rolling noise generation [1].

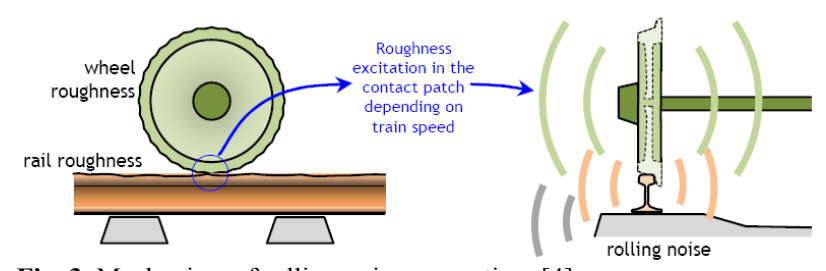

Fig. 3. Mechanism of rolling noise generation. [4]

There have been other theories besides Remington's about the causes of the rolling noise. King [9], for example, examined the possibility that the rolling noise is the result of an aerodynamic mechanism linked to the turbulence of the exterior layer around the bodies comprising the rolling device and reached to the conclusion that the aerodynamic noise is not an important source for velocities lower than $240 \mathrm{~km} / \mathrm{h}$.

Similarly, there have been attempts to explain the rolling noise by implementing the impact model into the wheel/rail system, designed by Feldman [10]. For this model, an equivalent roughness with a periodical evolution will be obtained from the roughness of the rolling surfaces - a stochastic order. To this purpose, a non-linear transformation is applied, which takes into account the roughness amplitude, the wheel radius and velocity. Based on the 
equivalent roughness, the spectrum of the excitation force is calculated, where this force represents the input element in the wheel/rail system.

The results here have shown that the impact model is not capable of giving an accurate description of the rolling phenomenon for the wheel on the rail. A series of theoretical aspects, insufficiently substantiated, have been pointed out at [11], such as the manner of evaluating the influence of the contact stiffness and the non-compliance of the action and reaction, since the force operating on the wheel is neither equal nor in the inverse direction to the one acting upon the rail.

The excitation of the wheel/rail system can also be triggered by the variation in the rail deformation occurring while passing over a constant load due to the fixation of the rail to the sleeper bays equally spaced on the ballast bed.

The frequency of this excitation is relatively low, i.e. $150 \mathrm{~Hz}$ at $325 \mathrm{~km} / \mathrm{h}$ with $0.6 \mathrm{~m}$ the distance between the sleeper bays- hence, the rolling noise cannot have an explanation. Among these theories on how the rolling noise is made, Remington model stands out, as it has received a strong validation from a large number of experiments. The most obvious fact that the production of the rolling noise underlies on the existence of the roughness in the rolling surfaces is proven by the trials done with specially lathed wheels so that the rolling surface have a sinusoidal roughness with controlled amplitude and wavelength [11]. The measurement of the noise under the bogie, between the two wheels of a sinusoidal circumferential profile, has confirmed that the noise spectrum is clearly dominated by a component whose frequency corresponds to the frequency induced by the sinusoidal roughness at the velocity.

\section{Mitigation Techniques and Methods for the Rolling Noise}

The contribution of those two noise sources - the wheel and the rail - to the overall noise level mainly depends on the design of wheels and track, the roughness spectrum and the train velocity [6]. Excepting for the high speeds, both the rail and the wheel are important noise sources, with similar contributions to the overall noise level. As a result, both sources should be taken into account for an efficient control of the rolling noise. For instance, when the wheel and the rail have an equal contribution to the overall noise level, a reduction of $10 \mathrm{~dB}$ on only one source will lead to the same action on the overall noise level by solely $2.5 \mathrm{~dB}$ [1]. This is the reason the measures for the rolling noise mitigation are focused, on the one hand, on the track infrastructure and, on the other hand, on the running gear. Table 3 shows an enumeration of such measures, along with the effects coming from the reduction of the rolling noise.

Table 3. Mitigation measures for the rolling noise [2].

\begin{tabular}{|c|c|c|c|}
\hline & Measure & Impact & Effect \\
\hline \multirow[t]{3}{*}{$\begin{array}{l}\text { The } \\
\text { infrastructure } \\
\text { measures }\end{array}$} & Rail dampers & Local & $\begin{array}{l}3-7 \mathrm{~dB}(\mathrm{~A}) \\
\text { (mostly around } 3 \\
\mathrm{~dB}(\mathrm{~A}) \text { attended) }\end{array}$ \\
\hline & Regular grinding & Local & $\begin{array}{l}10-12 \mathrm{~dB}(\mathrm{~A}) \text { (up } \\
\text { to } 20 \mathrm{~dB}(\mathrm{~A}) \text { at } \\
\text { very bad tracks) }\end{array}$ \\
\hline & $\begin{array}{l}\text { Special acoustic } \\
\text { grinding }\end{array}$ & Local & $\begin{array}{l}1-4 \mathrm{~dB}(\mathrm{~A}) \\
\text { (depending on } \\
\text { local rail } \\
\text { roughness }\end{array}$ \\
\hline
\end{tabular}

\begin{tabular}{|c|c|c|c|}
\hline & & & $\begin{array}{l}\text { conditions), } \\
\text { mostly around } 2 \\
\text { dB(A) attended }\end{array}$ \\
\hline & $\begin{array}{l}\text { Low height } \\
\text { barriers }\end{array}$ & Local & $8-10 \mathrm{~dB}(\mathrm{~A})$ \\
\hline & $\begin{array}{l}\text { Special barrier } \\
\text { tops: } \\
-2 \text { meter high } \\
-3-4 \text { meter high }\end{array}$ & Local & $\begin{array}{l}10 \mathrm{~dB}(\mathrm{~A}) \\
15 \mathrm{~dB}(\mathrm{~A})\end{array}$ \\
\hline \multirow{3}{*}{$\begin{array}{l}\text { The rolling } \\
\text { stock } \\
\text { measures }\end{array}$} & Wheel dampers & $\begin{array}{l}\text { Network } \\
\text { wide }\end{array}$ & $2-7 \mathrm{~dB}(\mathrm{~A})$ \\
\hline & $\begin{array}{l}\text { Braking blocks } \\
\text { type } \mathrm{K} \\
(\mathrm{K} \text { blocks) }\end{array}$ & $\begin{array}{l}\text { Network } \\
\text { wide }\end{array}$ & $\begin{array}{l}\text { Up to } 8 \mathrm{~dB}(\mathrm{~A})- \\
10 \mathrm{~dB}(\mathrm{~A})\end{array}$ \\
\hline & $\begin{array}{l}\text { Braking blocks } \\
\text { type LL } \\
\text { (LL blocks) }\end{array}$ & $\begin{array}{l}\text { Network } \\
\text { wide }\end{array}$ & $\begin{array}{l}\text { Up to } 8 \mathrm{~dB}(\mathrm{~A})- \\
10 \mathrm{~dB}(\mathrm{~A})\end{array}$ \\
\hline
\end{tabular}

\section{Rail dampers}

4.1. The constructive and functional principle of the rail damper. The efficiency of the rail damper

The rail dampers can be described as pre-formed or adjustable elements, usually mounted on the lateral sides of the rails (see Fig. 4), by using clips, bolts or glue, while some types have a part under the rail foot, acting to reduce the rolling noise by absorbing the vibrations of the rail.

There are discrete rail dampers and continuous rail dampers, in dependence on the manner of placement on the rail. Discrete rail dampers are mounted on the rail, at equal distance, usually half distance between every sleeper bay or the fasteners. The continuous rail damper is located along the rail, but this configuration is hardly used.

The rail dampers have to be mounted in such way so that they will not affect the normal construction of the track and obstruct the maintenance works.

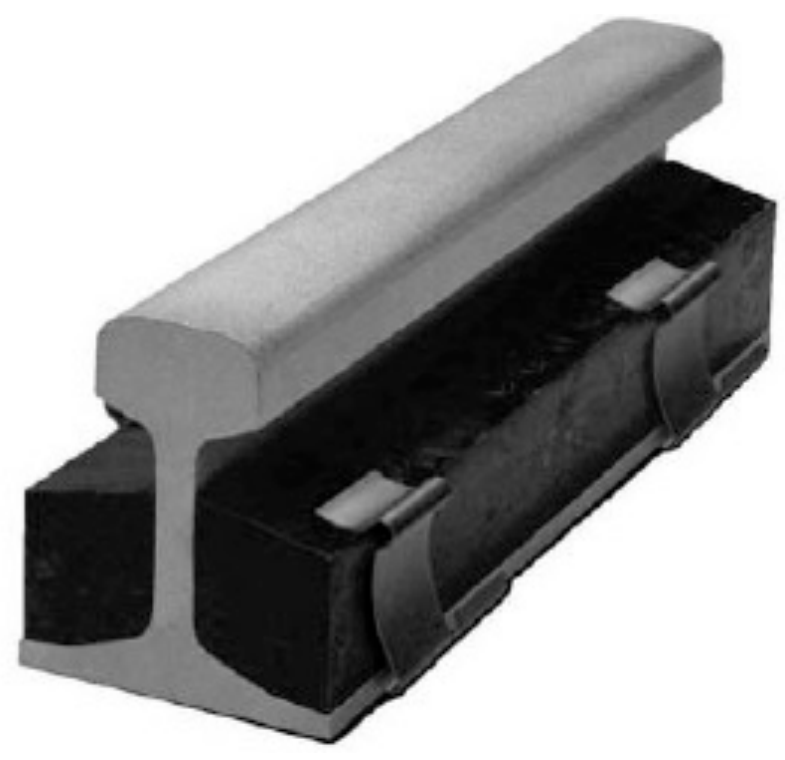

Fig. 4. The mounting of rail damper [12].

incorporated in an elastomeric material (see Fig. 5). The principle of the rail damper is relatively simple. The reduction in the oscillation of the vibrating rail is done by its coupling to a mass (steel elements in the damper) via a damped spring (the rubber between the rail and the steel elements in the damper). The rail vibration energy will be conveyed to the damper, the damper mass will also vibrate 
and this energy will be dissipated, due to the damping features in the rubber. The damper effect is similar with the increase of the rail damping level.

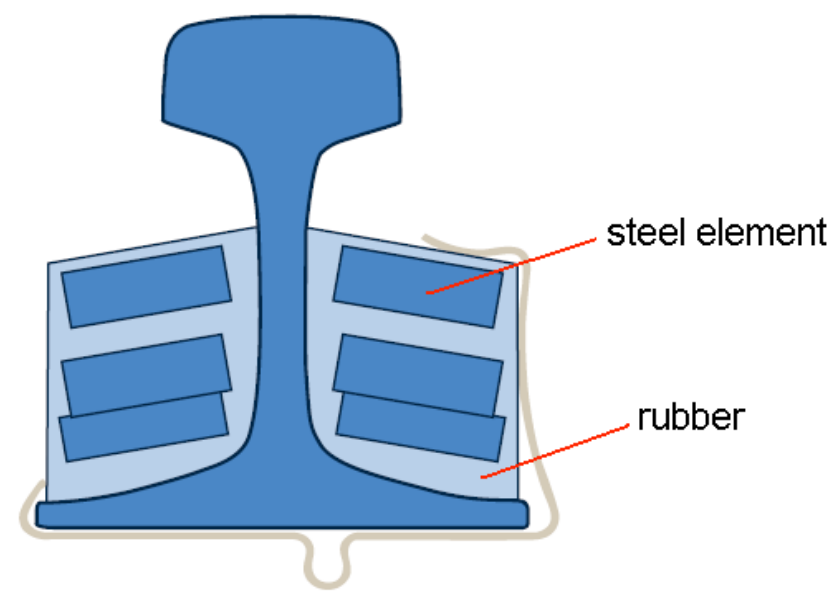

Fig. 5. The elements of the rail damping [12].

All the track dampers consist in steel elements The oscillation frequency at which the rail vibration energy is transferred to the damper depends on the stiffness and the damping coefficients of the rubber. A change in the type of rubber brings a modification in the range of the damper operating frequency or an improvement in the dissipation of the transferred energy. Similarly, the operating frequency of the rail damper depends on its model. An efficient damper is tuned in a wide range between 500 and $2000 \mathrm{~Hz}$, where the rail vibrations are important sources of rolling noise [4].

In reality, designing such damper is more complex than it seems at first. The issues come from the fact that rubber is a material whose features of stiffness and damping greatly rely on the load, frequency and temperature.

The performance of the rail damper is described by track decay rate (TDR); the higher TDR, the lower the noise emission. Practically speaking, TDR describes the characteristics of the rail vibration, more precisely the attenuation rate of vibrations along the rail. If $R$ is the reduction factor of the amplitude in the oscillation wavelength per meter, then TDR is given by $-20 \log _{10} R$. TDR is normally expressed in $\mathrm{dB} / \mathrm{m}$ and depends on the oscillation frequency. TDR is measured for both the vertical and the lateral vibrations of the rail.

For TDR of circa $10 \mathrm{~dB} / \mathrm{m}$, the reduction in the vibrations is so high that the emitted noise is no longer significant. As a consequence, increases of TDR over 10 $\mathrm{dB} / \mathrm{m}$ are not relevant. Since the rail dampers play the role of mitigating the rail vibrations, which corresponds to an increased TDR, it is important to remember that TDR should be under $10 \mathrm{~dB} / \mathrm{m}$ in the process of designing the damper.

TDR depends on the track construction parameters and the soil characteristics, which explains the large variations in TDR possible along the track. The high values of TDR at low frequencies, under $400 \mathrm{~Hz}$ - for the lateral vibrations, and smaller than $700 \mathrm{~Hz}$ for the vertical vibrations, are possible as a result of the coupling between the rail vibrations and the sleeper bays and soil. On the other hand, TDR greatly depends on the stiffness of the rail pad; for the stiff pad, the rail vibrations couple themselves with the vibrations in the sleeper bays and TDR is high; for the soft pad, the coupling between the rails and sleeper bays is weak and TDR will be low.

The reduction of the noise emission largely depends on the characteristics of the track system without dampers. For example, Fig. 6 shows the effect of the dampers in reducing the rolling noise emission, due to the rail. On most track systems, the power of sound emitted by the vehicle is much lower than the one coming from the rail, which is visible in the below diagrams. It also should be mentioned that the rail damper does not affect the wheel contribution. Consequently, the overall noise can be considerably reduced by mounting the rail dampers, if the track is the dominant source of noise; in this case, it is about a reduction of circa 4 $\mathrm{dB}(\mathrm{A})$.

The efficiency of the dampers also depends on train velocity. The rail dampers will therefore be inefficient at speeds lower than $30 \mathrm{~km} / \mathrm{h}$, where the traction noise is generally dominant. At high speeds, where the aerodynamic noise becomes significant, a reduced efficiency of the rail dampers is visible, of circa $1 \mathrm{~dB}(\mathrm{~A})$ [13].
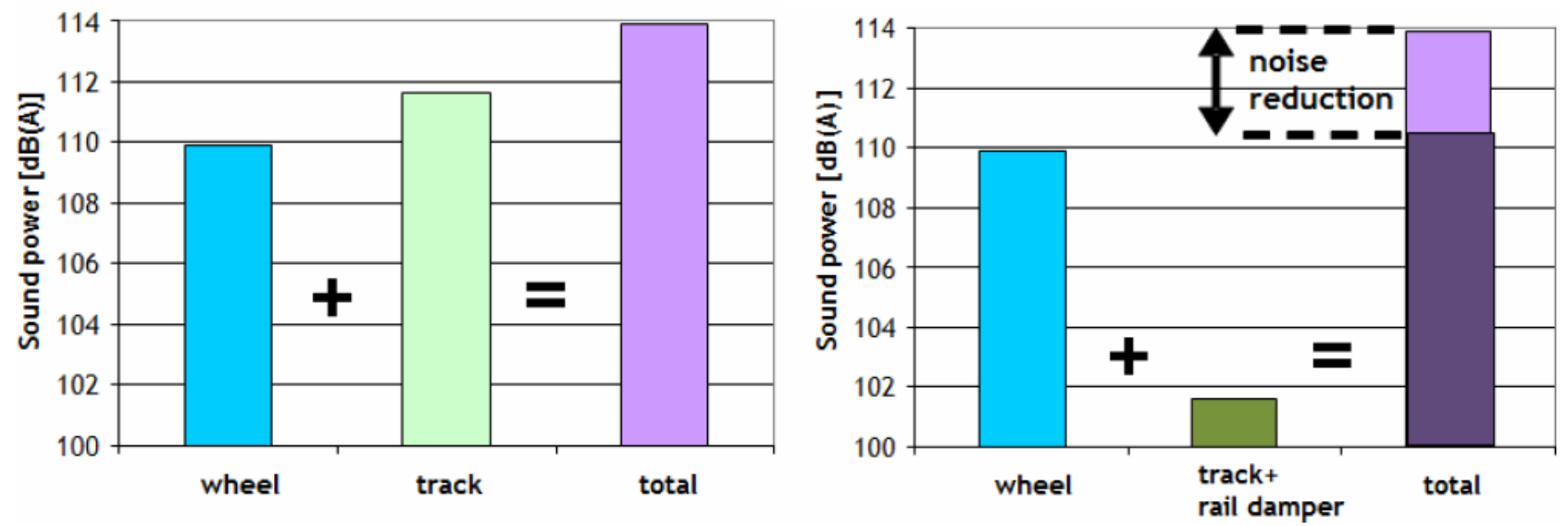

Fig. 6. Left: rolling noise on track without rail damper. Right: rolling noise on track with rail damper [14].

\subsection{Practical implementations of the rail dampers}

The first rail dampers were developed in the $90 \mathrm{~s}$ by European Rail Research Institute (ERRI) Committee C163 (Railway noise) within the project OFWHAT - Optimized Freight Wheels and Track, and by Société Nationale des
Chemins de Fer (SNCF) for the project VONA - Voie Optimisés vis à vis des Nuisances Acoustiques [15].

During the OFTWHAT experiments, tests were done with a rail damper consisting of cylindrical masses contained in an outer cylinder via an elastomeric sleeve (Fig. 7) that 
was mounted on the rail foot with stiff pads, on each side of the rail. According to the damper specifications, it was designed for two tuning frequencies, of $800 \mathrm{~Hz}$ and 1700 $\mathrm{Hz}$, both vertically and on the lateral side, with damping loss factors ranging from 0.25 to 0.5 .

The active mass was circa $6 \mathrm{~kg}$ for each sleeper bay [15]. The measurements have shown a reduction of the rail noise component of $2 \mathrm{~dB}(\mathrm{~A})$ for a train speed of $100 \mathrm{~km} / \mathrm{h}$. It is an unfortunate fact that tests were not done for the rail dampers - soft pad combination for which the use of the rail damper would have brought a considerably bigger benefit in the reduction of the rail noise component [1].

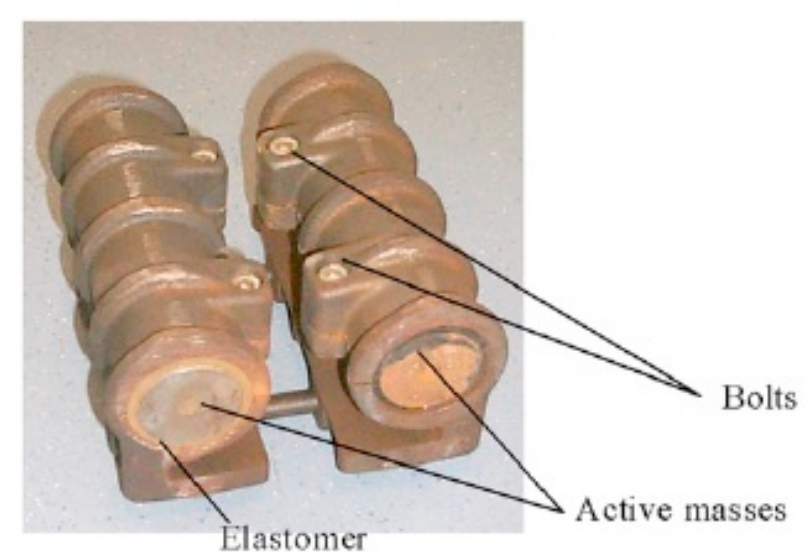

Fig. 7. Rail dampers developed in OFWHAT project [1].

Within the VONA project, rail dampers were designed to increase TDR, mainly for the vertical vibrations. They had rectangular steel blocks with the sizes of $200 \times 45 \times 45 \mathrm{~mm}$, to have an active mass of $3 \mathrm{~kg}$ on each side of the rail in each sleeper span. The dampers were glued to the top of the rail foot via an inclined block to give a vertical mounting surface, as in Fig. 8 [1, 15]. The initial design included a clamping arrangement at the edge of the rail foot and this solution proved to be less successful, due to the rail foot flexibility. A mass of $9 \mathrm{~kg}$ was added to each sleeper span. To have the tuning frequencies of $1000 \mathrm{~Hz}$ and $2000 \mathrm{~Hz}$, different elastomer elements were mounted in alternate sleeper spans. These dampers were estimated to have an effect of reducing the $4 \mathrm{~dB}$ noise emitted by rails, whereas the noise could be of $6 \mathrm{~dB}$ if combined with the optimized pads $[1,15]$.

The rail dampers were steadily developed between 1997 and 2000 for the Silent Track project, aiming to reduce the rolling noise component from the rail by $10 \mathrm{~dB}$. The Silent Track type damper, (Fig 9), seen as the most successful solution to increase TDR, includes steel masses incorporated into an elastomer with large damping, thus constituting itself into an adjustable damping two-degree freedom system, continuously attached along the rail on each side. This damper was mounted on a UIC60 type rail track, monobloc sleepers and $10-\mathrm{mm}$ studded rubber pads and tuned for the frequencies of $630 \mathrm{~Hz}$ and $1350 \mathrm{~Hz}$, with a damping loss factor higher than 0.35 .

The results of the measurements regarding the TDR under the above described conditions, on a length of 4 meters, are displayed in Fig. 10. TDRs are noticed to be very high at high frequencies but quite small at low frequencies, which can be explained by the fact that the tuning frequencies are ranged between 500 and $2000 \mathrm{~Hz}$. Similarly, the rail damper leads to the damping to the vertical vibrations at frequencies higher than $500 \mathrm{~Hz}$ for the track with soft pads. At low frequencies, TDRs are generally high (circa $10 \mathrm{~dB} / \mathrm{m}$ ), which proves that the mounting of dampers seems not to have any effects and it is not the rails but the sleepers that become the dominant noise source at those frequencies.

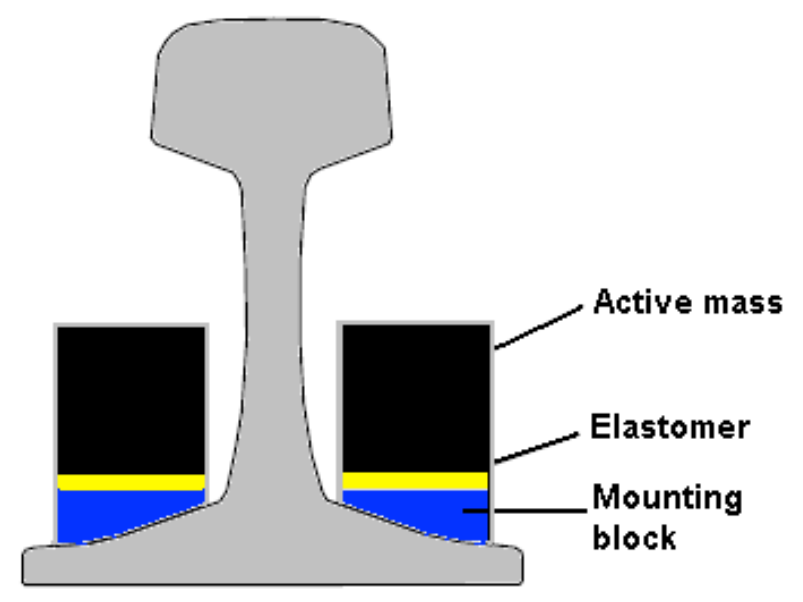

Fig. 8. Rail dampers developed in VONA project [1].

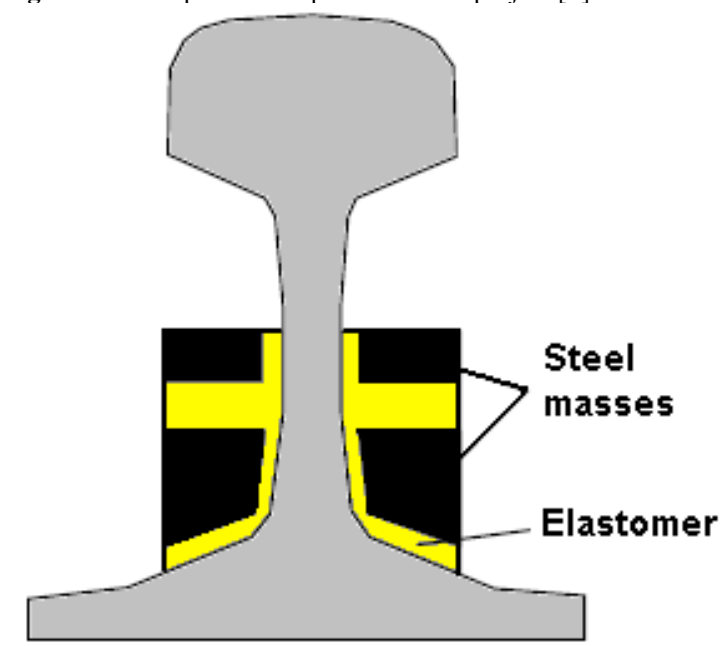

Fig. 9. Rail dampers developed in Silent Track project [1].

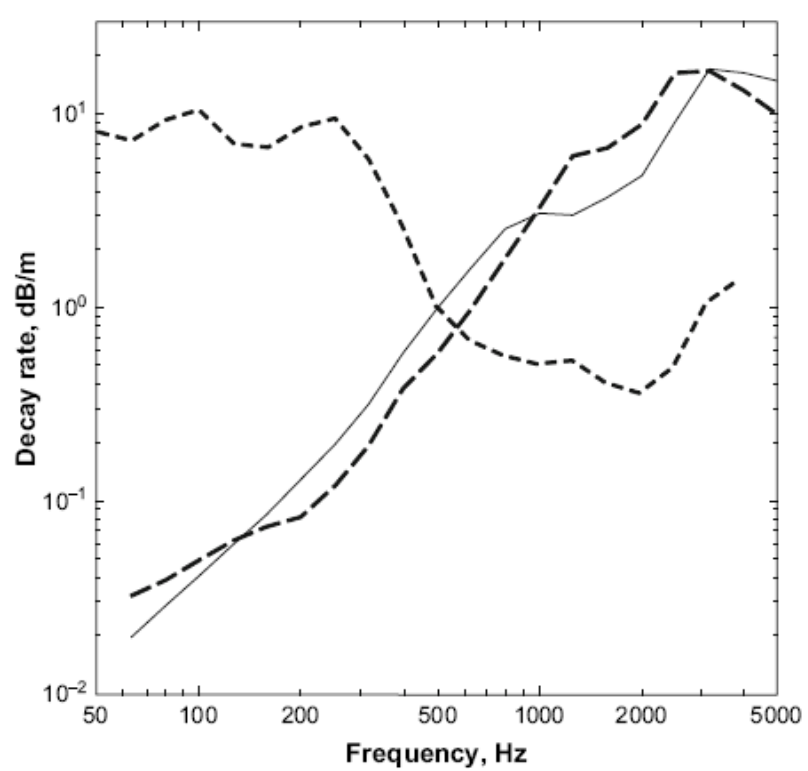

Fig. 10. Measured decay rates with the Silent Track rail damper: - , vertical vibration; - _ - , lateral vibration; - - -, vertical decay rates on track with soft pads [1]. 
For a track with a pad stiffness of $300 \mathrm{MN} / \mathrm{m}$, it has been estimated that the use of the Silent Track noise component due to the rail could be reduced by circa $6 \mathrm{~dB}(\mathrm{~A})$. It is obvious that the reduction will be smaller for a track with stiffer pads and higher for softer pads. The diagrams in fig 11 show the noise reduction coming from the use of this rail damper. The diagram (a) features the estimated results regarding the sound power radiated by the track, while the diagram (b) shows the measured sound pressure level for a vehicle fitted with a noise reducing wheel. The diagram (a) exhibits the efficiency of the damper at frequencies higher than $500 \mathrm{~Hz}$ and the results in diagram (b) demonstrate a reasonable agreement with the predictions. In fact, both diagrams feature a reduction of circa $6 \mathrm{~dB}(\mathrm{~A})$ of the rail component of noise.
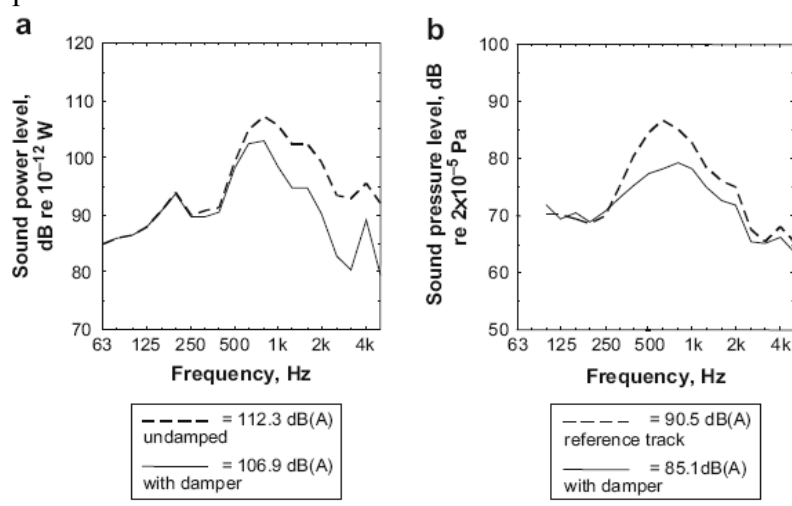

Fig. 11. Effect of Silent Track rail damper. (a) Predicted sound power from the track. (b) Measured total sound pressure from rolling noise at $100 \mathrm{~km} / \mathrm{h}$ using a vehicle fitted with a noise reducing wheel.

\subsection{Types of rail dampers}

In the light of the experience gained from the projects above, more manufacturers have developed various types of rail dampers, based on different constructive and functional principles. This section describes the most used rail dampers, namely the ones made by Schey \& Veith, TATA Steel, Vossloh and STRAIL [16].

Schey \& Veith have produced diverse types of rail dampers. In general, the damper is made of two or three active elements mounted on the rail by a basic sole plate (see Fig. 12). While for the dampers with two active parts, these parts are mounted on each lateral side of the rail, they are under the rail foot for the dampers with three active parts. Each element consists of a complex of alternate layers of steel elements - elastomer. The steel elements have different masses, which gives efficiency to the damper for an extended frequency range. For this damper, the total mass added to the rail is of circa $70 \%$.

TATA Steel has designed the rail damper known as TATA Steel SilentTrack, which includes three resonant steel masses distributed in such a way to shape into a vertically stacked arrangement incorporated in an elastomer with a high damping factor (see Fig 5). The elastomer has two functions - on the one hand, provides stiffness and massspring system damping and, on the other hand, protects the steel masses against corrosion. This type of damper is fixed on the lateral sides of the rail by elastic springs and glue see Fig 13. The total mass added to the rail is circa $30 \%$ [12].

The TATA Steel SilentTrack damper provides peak track noise levels with $3-6 \mathrm{~dB}$ and a wide frequency response over the important acoustic range for rail noise. The diagrams in Fig. 14 feature the sound pressure level (SPL) without SilentTrack damper - blue and with the SilentTrack damper - yellow.

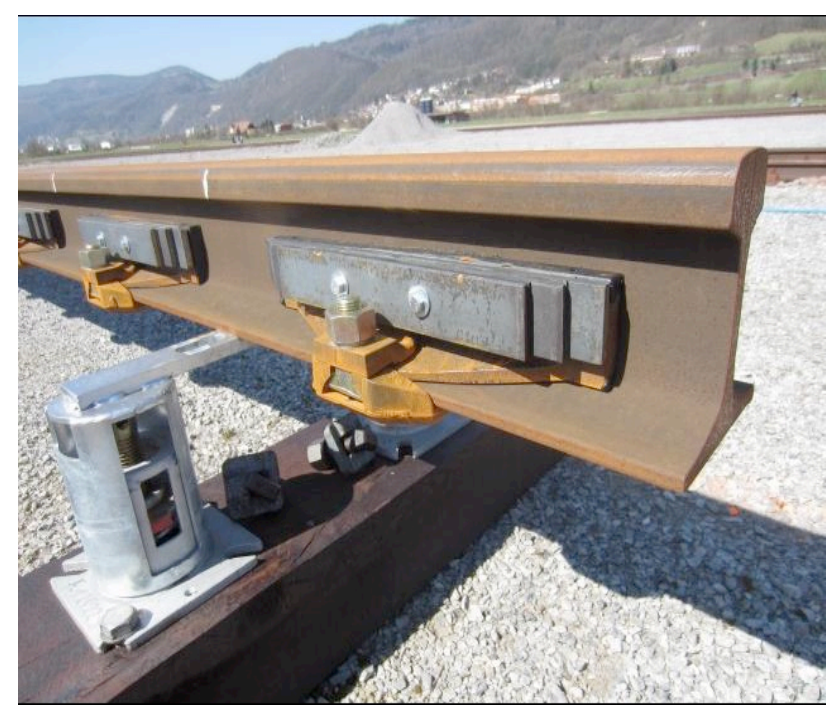

Fig. 12. Schey \& Veith damping rail [16].

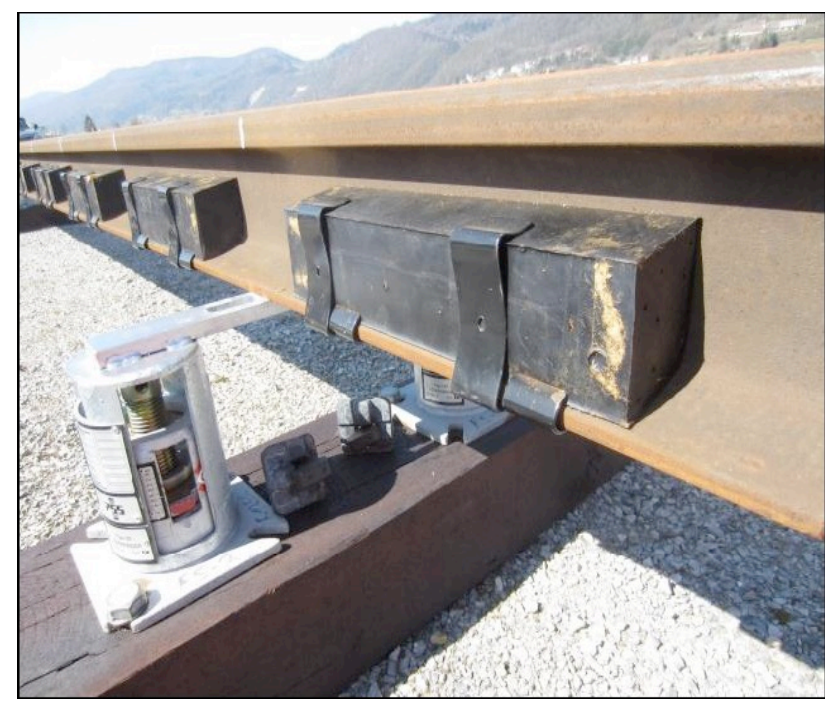

Fig. 13. TATA Steel damping rail [16].
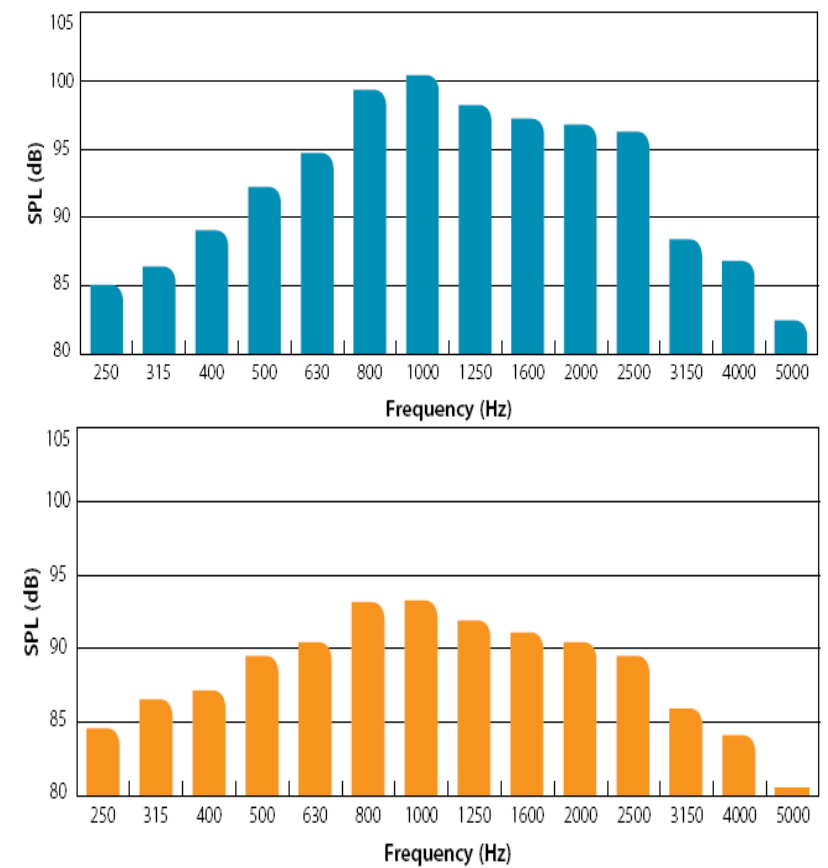

Fig. 14. The sound pressure level measured before SilentTrack and after SilentTrack [12]. 


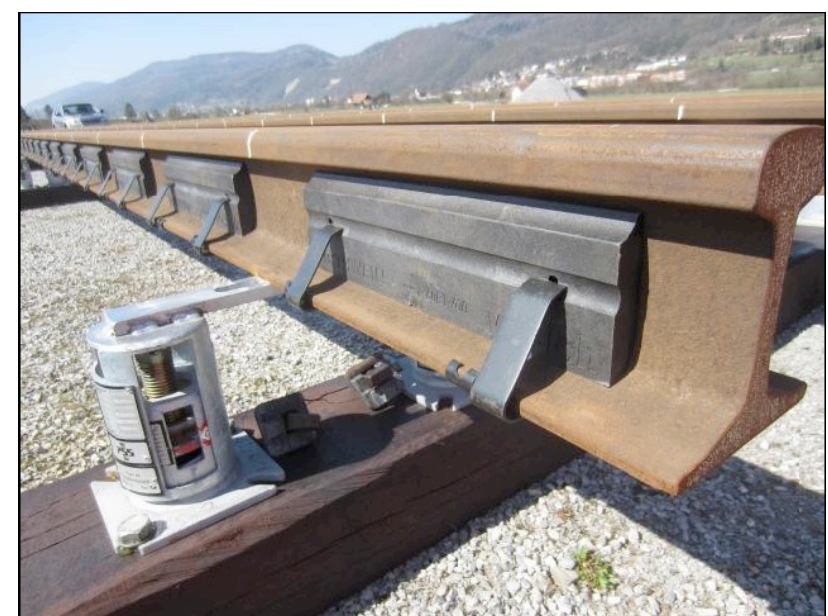

Fig. 15. Vossloh damping rail [16].

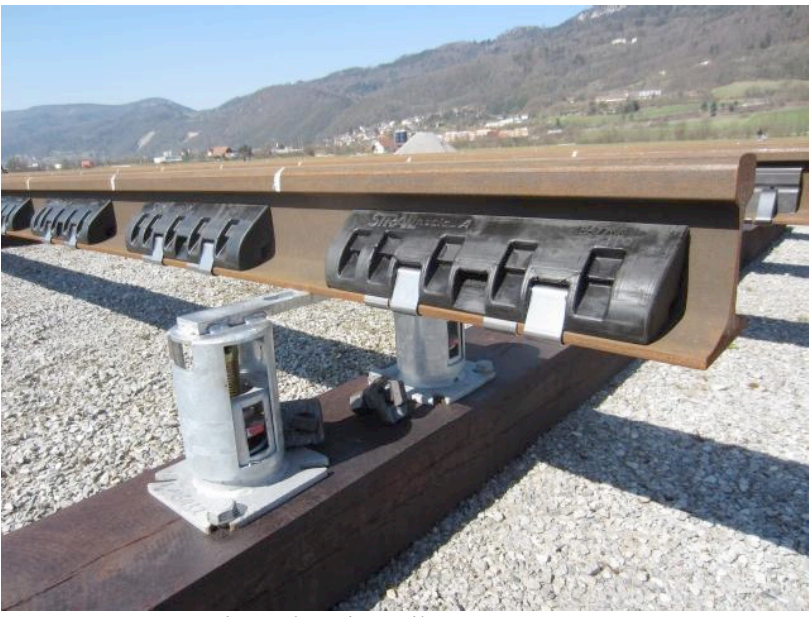

Fig. 16. STRAILastic_A damping rail [16].

Vossloh damping system (Fig 15) includes a steel-core composite element, fixed to the rail by steel clips.

STRAILastic_A (Fig. 16) is a rail damper manufactured by STRAIL from a heavy elastomer compound via a specialised vulcanising process. Unlike other rail dampers, this one does not contain steel. Based on a large mass, the damper operates like a mass damper. Plus, the elastic material raises the general damping effect. This is how the noise emission is reduced in two ways.

The STRAILastic_A damper has two versions. The steel-core STRAILastic_A inox (Fig. 17) can be fixed with rust-proof stainless steel clamps. The STRAILastic_A synth damper (Fig. 18) is made of a natural rubber mixture with a plastic clamp [18].

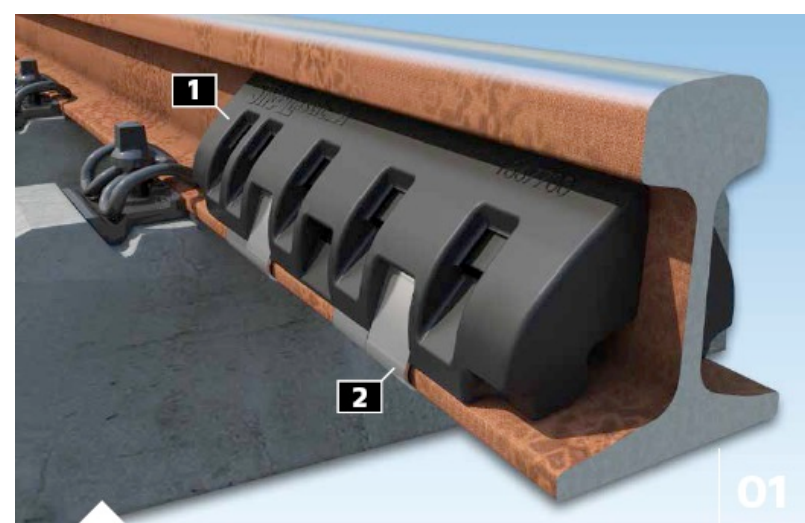

Fig. 17. STRAILastic_A inox: 1. rail damper made of a vulcanised natural rubber mixture with steel core; 2 . clamp made of stainless steel [18].

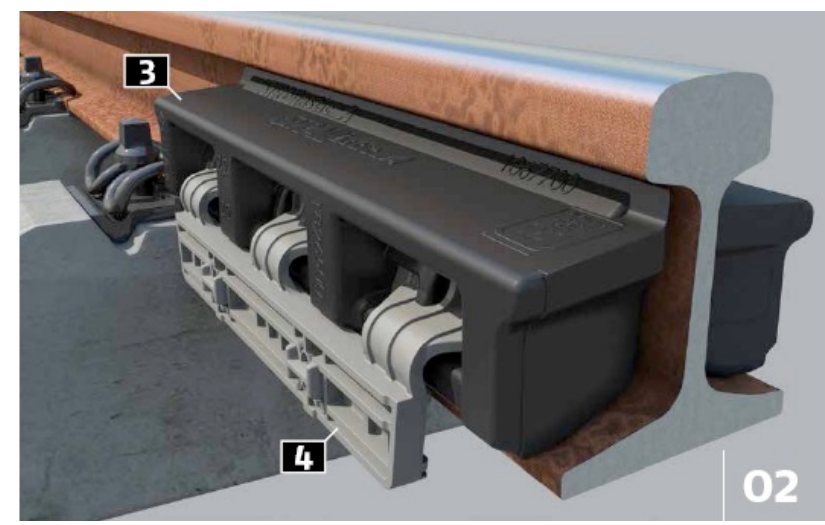

Fig. 18. STRAILastic_A synth: 3. rail damper made of a vulcanised rubber mixture; 4. clamp made of glass fibre reinforced plastic [18].

\subsection{Review of the most important results on the noise mitigation effects}

This section headlines a review of the most important results regarding the noise mitigation as a result of the use of the rail dampers in many European countries [14, 16].

In Austria, 2008, three types of dampers were tested Vossloh, Tata Steel and Schey \& Veith on a two-way curve (Innsbruck at Bludenz), on a mixed traffic line. On this curve, the track is built in wooden sleepers, UIC 60 rails and soft rail pads. The results of the noise measurements showed a decrease in the overall noise level for the first type of damper -between 0.7 and $1.1 \mathrm{~dB}$ for the BR4024 train and between 1.5 and $2.7 \mathrm{~dB}$ for the EC/IC trains. For the second type of damper, the reduction of the noise level was of $0.5 \ldots$ $0.9 \mathrm{~dB}$ for the BR4024 train and of $0.5 \ldots 3.5 \mathrm{~dB}$ for the EC/IC trains. Similarly, measurements were made to aim the TDR. They pointed out that the TDR rose with a tuned frequency of the rail damper (from $800 \mathrm{~Hz}$ to $1.6 \mathrm{kHz}$ ) by cca. $4 \mathrm{~dB} / \mathrm{m}$ for the best dampers.

Starting with 2008, the Vossloh and Tata Steel dampers were also installed in the Czech Republic for three track sections. The noise measurements proved that their efficiency is maximum in the vehicles fitted with a brake disk, while the efficiency is lower in the freight trains.

In Germany, for the Konjukturprogramm II project (2009-2011), five types of dampers were mounted in 29 different locations, on a total distance of $92 \mathrm{~km}$. The noise measurements were made on various trains with speeds between 50 and $200 \mathrm{~km} / \mathrm{h}$. The results highlight the fact that the noise reduction depends on both the damper and the train types, as seen in Table 4 where the positive values indicate this reduction. On average, the noise reduction is of $2 \mathrm{~dB}$ for the most competitive damper types.

Table 4. Noise reduction in $\mathrm{dB}$ for various types of dampers and trains [16].

\begin{tabular}{l|c|c|c|c|c}
\hline \multirow{2}{*}{$\begin{array}{l}\text { Train } \\
\text { type }\end{array}$} & \multicolumn{6}{|c}{ Rail damper type } \\
\cline { 2 - 6 } ICE & $\mathbf{1}$ & $\mathbf{2}$ & $\mathbf{3}$ & $\mathbf{4}$ & $\mathbf{5}$ \\
\hline $\mathrm{IC}$ & 2 & 1 & 2 & $\mathrm{NA}$ & $\mathrm{NA}$ \\
\hline $\mathrm{NV}$ & 1 & 1 & 2 & 1 & -1 \\
\hline ET S & 3 & $\mathrm{NA}$ & 1 & 1 & 0 \\
\hline $\begin{array}{l}\text { GZ } \\
\text { (freight } \\
\text { train) }\end{array}$ & 1 & 2 & 3 & 2 & NA \\
\hline Average & 2 & & & & 1 \\
\hline
\end{tabular}


In France, the rail dampers were tested on both the operational tracks and on bridges. The acoustic performance of the dampers on operational tracks was tested in 2004 on an operated conventional railway line with ballasted track, bibloc concrete sleepers, UIC60 rail, $9 \mathrm{~mm}$ stiff rubber rail pads. To test the dampers, three contiguous sections of a track were chosen, each of a length of $200 \mathrm{~m}$. There were no dampers mounted on the first section, the second was fitted with Tata Steel dampers and the Schrey \& Veit were mounted on the third section. The noise reduction at the operational speeds of more types of trains ranged between 1.7 and $2.9 \mathrm{~dB}(\mathrm{~A})$, as seen in Table 5. The performance of the dampers can be noticed not being sensitive to the train type. One year later, the noise tests were repeated and they proved different acoustic effects compared to the first measurements, in the sense that the noise reduction was between 4 and $5 \mathrm{~dB}$. The difference was explained by changes in the track.

The acoustic performance of the dampers on bridges has an explanation in the results from the tests made on Gavignot bridge, which is a steel bridge without ballast with the rails mounted on wooden sleepers directly fastened to the steel deck plate.

In spite of the simulations that were expecting a noise reduction by $5 \ldots 6 \mathrm{~dB}$, the measurements only showed $4 . .5$ $\mathrm{dB}$. But, on the other hand, these measurements exhibited an increase in the TDR following the mounting of the dampers, in compliance with the estimations.

Table 5. The acoustic effect of the rail dampers for various types of trains [16].

\begin{tabular}{l|c|c|c|c}
\hline Train type & $\begin{array}{c}\text { Freight } \\
\text { train }\end{array}$ & Stop train & IC & TGV \\
\hline $\begin{array}{l}\text { Operational } \\
\text { train speeds }\end{array}$ & $100 \mathrm{~km} / \mathrm{h}$ & $145 \mathrm{~km} / \mathrm{h}$ & $140 \mathrm{~km} / \mathrm{h}$ & $180 \mathrm{~km} / \mathrm{h}$ \\
$\begin{array}{l}\text { Acoustic } \\
\text { effect (in dB) }\end{array}$ & $1.7 \ldots 2.9$ & $2.3 \ldots 2.7$ & $2.5 \ldots 2.3$ & $2 \ldots 2.9$ \\
\hline
\end{tabular}

In the Netherlands, the Innovation Program Noise (IPG) was launched in 2001, where the performance of the Tata Steel and Schrey \& Veit dampers, was validated for an acoustic effect of $3 \mathrm{~dB}$.

Therefore, the conclusion reached was that the rail dampers are more lucrative on a double track than on the 1meter high noise barriers mounted on a side of the rail track. For this reason, the Dutch network had circa $106 \mathrm{~km}$ rail dampers mounted between 2007 and 2012 in areas where higher noise barriers would have been needed.

For 2008-2009, Sweden tested the efficiency of three different rail dampers - Schrey \& Veit, Tata Steel and STRAIL, which were mounted along the track, as in Fig. 19. The measurements targeted the noise level, TDR and the rail vibrations and the results in the damped sections were compared with the ones in the reference section. The track design is the standard design currently used in Sweden, respectively UIC 60 rails, resilient rail pads and monobloc concrete sleepers on ballast.

Prior to the measurements, the rails were grinded in order to achieve a comparable roughness for the Schrey \& Veit and Tata Steel dampers. Due to the fact that the rail section where the STRAIL dampers were mounted had a higher roughness than the others, the efficiency of these dampers could not be established in comparison with the other two types of dampers.

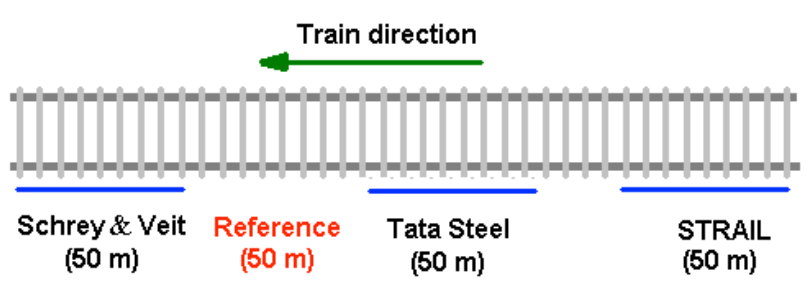

Fig. 19. The mounting of the rail dampers for the tests in Sweden [16].

The results concerning the effects of the dampers on the overall pass-by noise for the Schrey \& Veit and Tata Steel dampers during the passing of three types of trains - freight, Öresund and X2000 trains are featured in Table 6.

The measurements aiming TDR showed a significant increase versus the track without dampers, but still rather low for the $1 \ldots 3 \mathrm{kHz}$ interval, of only $3 \mathrm{~dB} / \mathrm{m}$.

Table 6. The acoustic effect of the rail dampers for various types of trains [16].

\begin{tabular}{|c|c|c|c|}
\hline $\begin{array}{l}\text { Train } \\
\text { type } \\
\text { Rail } \\
\text { damping } \\
\text { type }\end{array}$ & $\begin{array}{c}\text { Freight train } \\
\text { (Velocity } 90 \ldots \\
110 \mathrm{~km} / \mathrm{h} \text { ) }\end{array}$ & $\begin{array}{c}\text { Öresund } \\
\text { Train } \\
\text { (Velocity } 160 \\
\text { km/h) }\end{array}$ & $\begin{array}{c}\text { X2000 Train } \\
\text { (Velocity } 200 \\
\text { km/h) }\end{array}$ \\
\hline Tata Steel & $3 \mathrm{~dB}$ & $2 \mathrm{~dB}$ & $1.2 \mathrm{~dB}$ \\
\hline $\begin{array}{l}\text { Schrey \& } \\
\text { Veit }\end{array}$ & $2 \mathrm{~dB}$ to $3 \mathrm{~dB}$ & $1.8 \mathrm{~dB}$ & $1.9 \mathrm{~dB}$ \\
\hline
\end{tabular}

Switzerland tested all four types of dampers above, namely Schey \& Veith, TATA Steel, Vossloh and STRAILastic, in three situations: on a running line (Kerzers), on the bridges and within a testing program that had the purpose to analyse the costs and benefits at the network level for different types of rail dampers, as well as to evaluate the infrastructure.

During the Kerzers studies, the dampers were mounted on a track with UIC 60 rails, concrete sleepers, stiff rail pads and low roughness and the noise level, TDR and roughness were measured. A noise reduction was recorded, from circa 2 ... 3dB; for TDR, the increase was from $3.5 \mathrm{~dB} / \mathrm{m}$ to 6.5 $\mathrm{dB} / \mathrm{m}$ - for the lateral vibrations and from $3.5 \mathrm{~dB} / \mathrm{m}$ to 6.5 $\mathrm{dB} / \mathrm{m}$ - for the vertical vibrations.

The effects derived on the bridges after the mounting of the rail dampers with an elastic sleeper support were of 2 to $4 \mathrm{~dB}$, depending on the train type.

\section{Conclusions}

The noise emission during transport represents an issue from the perspective of environment pollution, no matter whether it is road, air or railway transportation. Even if the railway transport is admitted to having the greatest potential to operate with the least pollution than the road and air, the emission of railway noise has increased in the last decades, due to a higher speed, increase in the train tonnage and traffic intensification of the passenger and freight trains. More measures for reducing the rail sound pollution have been taken, to maintain the railway transport as a 'green transportation'.

The rail vehicles feature many noise sources, but this paper mentions the most important among them, which is the rolling noise. More techniques and methods have been established to mitigate this noise, either focused on the track 
infrastructure or the rolling device. An important measure that has proven itself able to provide satisfying results in the mitigation of the rolling noise is the use of the rail dampers.

Based on the available results up-to-date, the following conclusions can be drawn:

- There is a high variability of the results about the use of the rail dampers, from small noise increases to reductions of circa $3 \mathrm{~dB}$.

- The rail damper efficiency is influenced by a multitude of parameters, such as the track construction and with reference to, for instance, the rail pad stiffness, the soil characteristics, train speed or the traffic intensity. In many cases, there is no data for these parameters and, consequently, it is difficult to compare the results obtained in apparently similar circumstances. Even when some parameters influencing the efficiency of the rail dampers are known - eg. temperature or speed, their specific impact cannot be determined.

- When there is an issue about establishing the efficiency of the rail dampers, their influence upon the increase in the rail roughness should be also clarified. Since this is not the case, the evaluation of the damper efficiency is an unknown.
In a nutshell, the conclusion is that the correct evaluation of the efficiency of the rail dampers represents a challenging and costly issue - the testing procedures are expensive and time consuming. However, the knowledge of the efficiency of the rail dampers is a significant requirement prior to making large investments.

The efficiency of the rail dampers is not the only problem. Another one would be related to the effect of these dampers upon the track infrastructure. The rail dampers are a new element in the infrastructure and the impact upon the track maintenance, diagnosis, roughness and corrugation is not sufficiently known. Another concern is present herein, namely the supplementary mass added to the rail along with the mounting of the dampers.

\section{Acknowledgements}

This work was supported by a grant of the Romanian National Authority for Scientific Research and Innovation, CNCS/CCCDI - UEFISCDI, project number PN-III-P2-2.1PED-2016-0748, within PNCDI III.

This is an Open Access article distributed under the terms of the Creative Commons Attribution Licence

\section{References}

1. D. J. Thompson, Railway noise and vibration - Mechanisms, modelling and means, Elsevier (2009).

2. Reducing railway noise pollution - Study, European Parliament. Directorate General for Internal Policies Policy Department B: Structural and Cohesion Policies Transport and Tourism (2012).

3. T. Mazilu, Comfort at the rolling stock, (in Romanian), Ed. MatrixRom, Bucureşti (2003).

4. B. Hemsworth, Environmental Noise Directive Development of Action Plans for Railways, prepared for International Union of Railways (2008).

5. EC 2003, Working Group Railway Noise of the European Commission: Position Paper on the European strategies and priorities for railway noise abatement, Luxemburg, Publications Office (2003).

6. D.J. Thompson, C.J.C. Jones, T.P. Waters and D. Farrington, A tuned damping device for reducing noise from railway track, Applied Acoustics, 68, pp. 43-57 (2007).

7. E.K. Bender, P.J. Remington, The influence of rails on train noise, Journal of Sound and Vibration, 37 (3), pp. 321-334 (1974).

8. P. J. Remington, Wheel/rail noise - part IV: Rolling noise, Journal of Sound and Vibration, 46 (3), pp. 419-436 (1976).

9. W. F. King, On the role of aerodynamically generated sound in determining radiated noise levels of high speed trains, Journal of Sound and Vibration, 54 (3), pp. 361-378 (1977).

10. J. Feldman, A theoretical model for structure-borne sound excitation of a beam and a ring in rolling contact, Journal of Sound and Vibration, 116 (3), pp. 527-543 (1987).

11. ORE, C 163/RP 18, Etude fondamentale pour reduction du bruit de roulement, Utrecht (1990).

12. SilentTrack. Reducing railway noise, TATA STEEL - Product brochure (2014).

13. High Speed Railway Noise - Assement of Mitigation Measures, Letourneaux, IWRN2007 (2007).

14. Railway noise. Technical Measures Catalogue, Coordinator: Nick Craven, International Union of Railways (2013).

15. D.J. Thompson and P.E. Gautier, A review of research into wheel/rail rolling noise reduction Proceedings of the Institution of Mechanical Engineers, Part F: Journal of Rail and Rapid Transit, 220, (4), pp. 385-408 (2006).
16. E. Scossa-Romano and J. Oertli, Rail Dampers, Acoustic Rail Grinding, Low Height Noise Barriers - A report on the state of the art, prepared for International Union of Railways (2012).

17. Vossloh Fastening Systems Rail web damping system Presentation SZDC (2010).

18. STRAILastic_A. The noise-absorber system - Product brochure. 